\title{
Cardiovascular Risk Factors from Another Point of View
}

\author{
Péter Balázs Oltean, István Kovács, Roxana Hodas, Theodora Benedek \\ Center of Advanced Research in Multimodality Cardiac Imaging, Cardio Med Medical Center, Târgu Mureș, Romania
}

\section{CORRESPONDENCE \\ István Kovács \\ Str. 22 Decembrie 1989 nr. 76 \\ 540124 Târgu Mures, Romania \\ Tel: +40 265217333 \\ E-mail: kov_istvan@yahoo.com}

\section{ARTICLE HISTORY}

Received: December 12, 2020

Accepted: January 15, 2021

Published online February 18, 2021
Péter Balázs Oltean • Str. 22 Decembrie 1989 nr. 76 540124 Târgu Mures, Romania. Tel: +40 265217333 , E-mail: olteanbalazs1@gmail.com

Roxana Hodas • Str. 22 Decembrie $1989 \mathrm{nr} .76$ 540124 Târgu Mureș, Romania. Tel: +40 265217333 , E-mail: roxana.hodas@yahoo.ro

Theodora Benedek • Str. 22 Decembrie 1989 nr. 76, 540124 Târgu Mureș, Romania. Tel: +40 265217333 , E-mail: theodora.benedek@gmail.com

\begin{abstract}
Cardiovascular diseases remain the main cause of death in western societies. This contributes to the appearance of new diagnostic and treatment methods addressed to reduce the burden of cardiovascular diseases. In the last decades new imaging methods have emerged; furthermore, routine biomarkers were found to be useful in cardiovascular risk stratification. Data reviewed in this article emphasize the multifactorial etiology of cardiovascular disease. The authors describe the role of inflammation in the precipitation and progression of atherosclerosis and atrial fibrillation. Affordable and well-known inflammatory markers can be used alone or in combination with new imaging methods for a better cardiovascular risk stratification. Coronary computed tomographic angiography findings and inflammatory markers are capable to identify patients with high risk of major adverse cardiovascular events or atrial fibrillation. Furthermore, they also have an important role in the choice of treatment strategy and follow-up.
\end{abstract}

Keywords: cardiovascular diseases, biomarker, risk factor

\section{INTRODUCTION}

Europe's population is getting older. Population ageing is the most significant demographic and social trend of the 21 st century, affecting every country in the world. The incidence of ischemic heart disease (IHD) and atherosclerosis increases with age, appearing 6-9 years earlier in men than in women. Each year, IHD causes millions of deaths worldwide, and atherosclerotic disease remains the most common cause of death in developed countries. ${ }^{1}$ In the last decades, the mortality rate of cardiovascular disease has decreased significantly due to improved diagnosis and treatment methods and primary prevention. ${ }^{2}$ Patients with coronary artery disease can be completely asymptomatic in the early phases, being diagnosed in advanced stages, when the treatment is difficult and the prognosis can be poor. In most cases the symptoms are caused by heart failure and different types of arrhythmias. In elderly patients, the onset of atrial fibrillation can be the first sign of myocardial hypoperfusion. ${ }^{3,4}$ In addition to well-known risk factors, acute or chronic inflammatory states can lead to plaque instability, atherosclerosis progression, and adverse cardiovas- 
cular events. ${ }^{5}$ The most common causes of death in this group of patients are sudden death, acute heart failure, and malignant ventricular arrhythmias, caused by acute coronary syndrome (ACS) and myocardial infarction (MI). ${ }^{6}$ These patients are very vulnerable to the slightest internal or external stimulus. For this reason, patients at high risk of atherosclerosis require regular screening and need to be diagnosed before the acute event. One of the most accurate methods is coronary computed tomography angiography (CCTA), which is capable to assess several aspects of coronary atherosclerosis such as the presence of atherosclerosis, stenosis, markers of potential plaque instability, and atheroma size. ${ }^{7}$

\section{ASSESSMENT OF CORONARY ARTERY DISEASE}

In the last decade, the diagnosis of coronary artery disease has become easier, faster, and more accurate. In the past, electrocardiography was the only diagnostic and screening method. The appearance of coronary angiography contributed to the diagnosis of significant coronary stenosis but without providing any information about the structure of the plaques. Nowadays, this method is reserved for acute cases when angioplasty is needed, and it cannot be used widespread for screening and for the assessment of cardiovascular risk. Computed tomography has become an indispensable method in cardiology in the last decade. Numerous large-scale randomized studies have demonstrated that this method has an excellent diagnostic accuracy, in both symptomatic and asymptomatic patients. ${ }^{8,9}$ Several trials, such as HEART (Scottish Computed Tomography of the Heart) and PROMISE (Prospective Multicenter Imaging Study for Evaluation of Chest Pain), demonstrated that the rate of MI can be significantly reduced using a CCTA-guided treatment strategy. ${ }^{10-13}$ This noninvasive imaging method is able to diagnose patients with coronary atherosclerosis from the early stages and is able to determine long-term cardiovascular risk.

Another important feature of this investigation is that it is able to provide information about the structure of coronary plaques. This technique is capable to determine vulnerable plaque features, such as low-attenuation plaque, positive remodeling, spotty calcification, and napkin-ring sign. ${ }^{14-16}$ In a meta-analysis $(\mathrm{n}=13,977)$, Nerlekar et al. reported a strong correlation between high-risk plaque features and the incidence of major adverse cardiovascular events (MACE), the presence of two criteria increasing the risk of MACE 9-fold. ${ }^{17}$

\section{CARDIOVASCULAR RISK IN PATIENTS WITH CHRONIC INFLAMMATORY DISEASES}

Atherosclerosis is the cause and the consequence of inflammation. This systemic disease is associated with a low-grade inflammation of the arterial wall at the level of medium- and large-sized arteries. ${ }^{18}$ Galkina et al. showed in their review that inflammation has an important role in all phases of atherosclerosis. ${ }^{19}$ Several studies demonstrated a positive correlation between chronic inflammatory state and atherosclerosis. We found several clinical trials in the literature dealing with the incidence of cardiovascular disease in patients with chronic inflammatory diseases. Literature data suggest that chronic inflammatory rheumatic diseases (CIRD), such as systemic lupus erythematosus (SLE), rheumatoid arthritis, and seronegative SpA, are associated with significant cardiovascular (CV) morbidity and mortality. ${ }^{20}$ In a meta-analysis, Aviña-Zubieta et al. concluded that CIRD patients have an increased prevalence of CV disease. ${ }^{21}$ The ATHERODENT clinical trial showed a positive correlation between periodontal disease, atherosclerosis, and plaque vulnerability. ${ }^{22}$ The correlation between atherosclerosis and chronic inflammatory disorders of the gastrointestinal tract is not elucidated. ${ }^{23,24}$ Multiple cohort studies reported a significant correlation between inflammatory bowel disease (IBD) and the incidence of MACE. ${ }^{25-27}$ In a French cohort study ( $\mathrm{n}=210,162)$, Kirchgesner et al. found an increased risk of acute arterial events in patients with IBD. Furthermore, they reported a high risk in young patients. In their group, the risk of MACE increased proportionally with the number, duration, and severity of acute events. ${ }^{28}$ This finding was also confirmed by an Asian and Danish cohort study, where the authors described a strong correlation between cardiovascular morbidity and mortality in young patients with IBD. ${ }^{25,29}$ Weissman et al. concluded in their review that IBD is a risk factor for atherosclerosis and MACE, especially in young and female patients. ${ }^{30}$

\section{INFLAMMATION AND MAJOR CARDIOVASCULAR EVENTS}

Inflammation has also an important role in the precipitation of ACS, as the inflammatory state can lead to plaque disruption. The correlation between inflammation and MACE is complex and not fully understood. ${ }^{31}$ Many types of inflammatory cells are involved in the mechanism of coronary plaque destabilization. Macrophages and neutrophils play an important role in plaque disruption and atherosclerosis progression. ${ }^{32}$ These cells secrete matrix 
metalloproteinase-9 (MMP-9). A disturbance in the ratio of MMP-9 and tissue inhibitors of matrix metalloproteinase (TIMP-1) leads to arterial extracellular matrix breakdown and eventually plaque rupture. ${ }^{33}$ Several clinical trials demonstrated that patients with ACS have a significantly higher MMP-9 level. ${ }^{34-36}$ The authors describe other types of MMPs, such as MMP-1 and MMP-2, which are also increased in patients with ACS. Wang et al., in a recent review, concluded that the acquired immune system also contributes to coronary plaque vulnerability. ${ }^{31}$ Helper T cells, especially Th1 cells, are characterized by the production of pro-inflammatory cytokines, such as interferon- $\gamma$ and tumor necrosis factor- $\alpha$, which contributes to plaque disruption in ACS..$^{37,38}$ Researchers investigated the correlation between plaque vulnerability and different types of microorganisms but without finding a significantly correlation. ${ }^{39}$ Only a few studies reported that infection with Chlamydia, Mycoplasma pneumoniae and some viruses may have an additional higher cardiovascular risk. ${ }^{40-42}$

An acute inflammatory state can lead to ACS without the presence of any coronary artery occlusion. This indirect mechanism of ACS is characterized by the increased oxygen and metabolic needs of the myocardium, and it is called demand ischemia or myocardial infarction(MI) type $2.43,44$

\section{THE ROLE OF C-REACTIVE PROTEIN IN CORONARY ARTERY DISEASE}

C-reactive protein (CRP) is a widely used inflammatory biomarker, its level being increased in every type of inflammatory disease. It is a valuable marker not only for diagnosis, but also for monitoring. Determination of CRP is easy, inexpensive, and highly available. Recently, the role of CRP in cardiology has been demonstrated. Studies suggest that there is a strong correlation between the level of high-sensitivity (hs)-CRP and MACE.

The role of hs-CRP in primary cardiovascular prevention is not so clear. Several large clinical trials demonstrated that an increased level of hs-CRP is associated with a higher cardiovascular risk. Ridker et al., in several prospective studies, demonstrated that patients with elevated hs-CRP are prone to develop MACE. ${ }^{45-49}$ They described that these patients, without cardiovascular disease, have a three times higher risk for myocardial infarction. They also emphasize that hs-CRP was the best predictor of $\mathrm{CV}$ risk among female patients after the onset of menopause. Other authors have also demonstrated this correlation. ${ }^{50,51}$ However, others did not find a significant correlation. ${ }^{52-54}$
The level of hs-CRP has also an important role in patients with IHD. Studies have shown that hs-CRP is a marker of acute events in patients with IHD. Won-Woo et al. assessed the correlation between the level of hs-CRP and CCTA findings. They concluded that the combination of imaging and inflammatory markers contributes to a better CV risk stratification. ${ }^{55}$ Takashi et al. found a significant correlation between the level of hs-CRP and the grade of necrosis of culprit lesion, assessed with IVUS. ${ }^{56,57}$ Trans-lesion CRP gradient was calculated by Inoue et al., and they found a higher level distal to the site of coronary plaque. They also reported a higher level in case of unstable plaques. ${ }^{58}$ In the VISTA- 16 trial $(n=5,145)$ the authors reported that elevated hs-CRP levels after an acute cardiovascular episode and subsequent level increases are associated with adverse outcomes. ${ }^{59}$ Several other trials have confirmed this correlation. ${ }^{60,61}$ In 2018, our research group reported that hs-CRP level is in correlation with infarct size in STEMI patients. ${ }^{62}$

\section{INFLAMMATION AND ATRIAL FIBRILLATION}

Inflammation can be either a cause or a consequence of atrial fibrillation (AF). Data from the literature suggest that inflammation has an important role in the structural and electrical remodeling of the atrium. Inflammation causes atrial fibrosis, gap junction modulation, and calcium homeostasis disturbance. These modifications promote ectopic atrial activity and aberrant impulse conduction. ${ }^{63}$ Studies describe a correlation between systemic inflammation and AF. Patients with IBD, CIRD, psoriasis, SLE or sclerosis are more predisposed to AF. ${ }^{64-67}$ Local inflammatory conditions, such as myocarditis or pericarditis, are also associated with a high risk of AF. ${ }^{68}$

The determination of hs-CRP level can also be useful in patients with AF. There are studies that describe an increased level of this inflammatory marker in case of persistent AF, compared to paroxysmal AF. ${ }^{69} \mathrm{Wu}$ et al. demonstrated in a meta-analysis that a higher baseline hs-CRP level is associated with a higher risk of AF recurrence after catheter ablation and electrical cardioversion. ${ }^{70}$ An elevated white blood cell (WBC) count is also in correlation with the incidence of $\mathrm{AF}$, as confirmed by several studies such as the Framingham Heart Study. ${ }^{71}$ Weymann et al., in their meta-analysis, did not find any correlation between the onset of AF and WBC count. However, they suggest that WBC may have a predictive role in the recurrence of AF. Some authors consider that the determination of the neutrophil/lymphocyte ratio is more accurate. ${ }^{72,73}$ 


\section{CONCLUSIONS}

In the last decade, due to the increased rate of cardiovascular diseases, further investigations were conducted to identify novel cardiovascular risk factors. Systemic inflammation is directly associated not only with ischemic heart disease, but also with the risk to develop atrial fibrillation. The pathophysiology of atrial fibrillation is multifactorial, inflammation being both a cause and a consequence of this condition. Inflammation can promote ectopic atrial activity and aberrant impulse conduction, and the level of circulating inflammatory markers may predict the risk of recurrence. Inflammatory biomarkers, especially in combination with imaging markers, can be used for a better stratification of cardiovascular risk.

\section{CONFLICT OF INTEREST}

Nothing to declare.

\section{ACKNOWLEDGEMENT}

This research was supported via the research grant no. 103544/2016, contract number 26/01.09.2016, entitled "Increasing the research capacity in the field of vulnerable plaque imaging, based on advanced nanoparticles, fusion imaging and computational simulation - PlaqueImage", financed by the Romanian Ministry of European Funds, the Romanian Government and the European Union.

\section{REFERENCES}

1. World Health Organization. Global diffusion of eHealth: making universal health coverage achievable: report of the third global survey on eHealth. World Health Organization, 2017.

2. Finegold JA, Asaria P, Francis DP. Mortality from ischaemic heart disease by country, region, and age: statistics from World Health Organisation and United Nations. Int J Cardiol. 2013;168:934-945.

3. Kannel WB, Abbott RD, et al. Epidemiologic features of chronic atrial fibrillation: the Framingham study. N Engl J Med. 1982;306:1018-22.

4. Kralev S, Schneider K, et al. Incidence and severity of coronary artery disease in patients with atrial fibrillation undergoing first-time coronary angiography. PLoS One. 2011;6:e24964.

5. Golia E, Limongelli G, Natale F, et al. Inflammation and cardiovascular disease: from pathogenesis to therapeutic target. Curr Atheroscler Rep. 2014;16:435.

6. Goldberger JJ, Cain ME, Hohnloser SH, et al. American Heart Association/ American College of Cardiology Foundation/Heart Rhythm Society scientific statement on noninvasive risk stratification techniques for identifying patients at risk for sudden cardiac death: a scientific statement from the American Heart Association Council on Clinical Cardiology Committee on Electrocardiography and Arrhythmias and Council on Epidemiology and Prevention. Circulation. 2008;118:1497-518.

7. Schmermund A, Eckert J, Schmidt M, et al. Coronary computed tomography angiography: a method coming of age. Clin Res Cardiol. 2018;107:40-48.

8. Hadamitzky M, Taubert S, Deseive S, et al. Prognostic value of coronary computed tomography angiography during 5 years of follow-up in patients with suspected coronary artery disease. Eur Heart J. 2013;34:3277-3285.

9. Hadamitzky M, Achenbach S, Al-Mallah M, et al. Optimized prognostic score for coronary computed tomographic angiography: results from the CONFIRM registry (COronary CT Angiography EvaluatioN For Clinica Outcomes: An InteRnational Multicenter Registry). J Am Coll Cardiol 2013;62:468-476

10. SCOT-HEART investigators. CT coronary angiography in patients with suspected angina due to coronary heart disease (SCOT-HEART): an openlabel, parallel-group, multicentre trial. Lancet. 2015;385:2383-2391.

11. Newby DE, Adamson PD, Berry C, et al. SCOT-HEART Investigators. Coronary CT angiography and 5-year risk of myocardial infarction. N Eng J Med. 2018;379:924-933.

12. Adamson PD, Williams MC, Dweck MR, et al. SCOT-HEART Investigators Guiding therapy by coronary CT angiography improves outcomes in patients with stable chest pain. J Am Coll Cardiol. 2019;74:2058-2070.

13. Douglas PS, Hoffmann U, Patel MR, et al. PROMISE Investigators. Outcomes of anatomical versus functional testing for coronary artery disease. N Engl J Med. 2015;372:1291-1300.

14. Budoff MJ, Dowe D, et al. Diagnostic performance of 64-multidetector row coronary computed tomographic angiography for evaluation of coronary artery stenosis in individuals without known coronary artery disease: results from the prospective multicenter ACCURACY (Assessment by Coronary Computed Tomographic Angiography of Individuals Undergoing Invasive Coronary Angiography) trial. J Am Coll Cardiol. 2008;52:1724-1732.

15. Maurovich-Horvat $\mathrm{P}$, Ferencik $\mathrm{M}$, et al. Comprehensive plaque assessment by coronary CT angiography. Nat Rev Cardiol. 2014;11:390-402.

16. Miller JM, Rochitte CE, et al. Diagnostic performance of coronary angiography by 64-row CT. N Engl J Med. 2008;359:2324-2336.

17. Nerlekar N, Ha FJ, et al. Computed tomographic coronary angiographyderived plaque characteristics predict major adverse cardiovascular events: a systematic review and meta-analysis. Circ Cardiovasc Imaging. 2018;10:e006973.

18. Soraya T. Inflammation in atherosclerosis. Elsevier. 2016;109(12):708-715

19. Galkina E, Ley K. Immune and inflammatory mechanisms of atherosclerosis. Annu Rev Immunol. 2009;27:165-197.

20. Arida A, Protogerou AD, et al. Systemic Inflammatory Response and Atherosclerosis: The Paradigm of Chronic Inflammatory Rheumatic Diseases. Int J Mol Sci. 2018;19:1890.

21. Aviña-Zubieta JA, Choi HK, Sadatsafavi M, et al. Risk of cardiovascular mortality in patients with rheumatoid arthritis: A meta-analysis of observational studies. Arthritis Care Res. 2008;59:1690-1697.

22. Rodean IP, Lazar L, Opincariu D, et al. Association between periodontal disease, coronary calcium score and markers of subclinical atherosclerosis in patients with unstable angina - a CT-based sub-study from the ATHERODENT clinical trial. European Heart Journal - Cardiovascular Imaging. 2020;21:jez319.299.

23. Dorn SD, Sandler RS. Inflammatory bowel disease is not a risk factor for cardiovascular disease mortality: results from a systematic review and meta-analysis. Am J Gastroenterol. 2007;102:662-667.

24. Zanoli L, Signorelli SS, Inserra G, Castellino P. Subclinical Atherosclerosis in Patients With Inflammatory Bowel Diseases: A Systematic Review and Meta-Analysis. Angiology. 2017;68:463.

25. Kristensen SL, Ahlehoff O, Lindhardsen J, et al. Disease activity in inflammatory bowel disease is associated with increased risk of myocardia infarction, stroke and cardiovascular death - a Danish nationwide cohort study. PLoS One. 2013;8:e56944.

26. Yarur AJ, Deshpande AR, Pechman DM, et al. Inflammatory bowel disease is associated with an increased incidence of cardiovascular events. Am J Gastroenterol. 2011;106:741-747.

27. Aniwan S, Pardi DS, Tremaine WJ, Loftus EV Jr. Increased Risk of Acute Myocardial Infarction and Heart Failure in Patients With Inflammatory Bowel Diseases. Clin Gastroenterol Hepatol. 2018;16:1607-1615.

28. Kirchgesner J, Beaugerie L, Carrat F for the BERENICE study group, et al. Increased risk of acute arterial events in young patients and severely active IBD: a nationwide French cohort study. Gut. 2018;67:1261-1268.

29. Tsai MS, Lin $\mathrm{CL}$, Chen HP, Lee $\mathrm{PH}$, Sung FC, Kao CH. Long-term Risk of Acute Coronary Syndrome in Patients with Inflammatory Bowel Disease: A 13-year Nationwide Cohort Study in an Asian Population. Inflammatory Bowel Diseases. 2014;20:502-507.

30. Weissman S, Sinh P, Mehta TI, et al. Atherosclerotic cardiovascular disease in inflammatory bowel disease: The role of chronic inflammation. World $J$ Gastrointest Pathophysiol. 2020;11:104-113.

31. Wang H, Liu Z, Shao J, et al. Immune and Inflammation in Acute Coronary Syndrome: Molecular Mechanisms and Therapeutic Implications. J Immunol Res. 2020;2020:4904217. 
32. Libby P, Tabas I, Fredman G, Fisher EA. Inflammation and its resolution as determinants of acute coronary syndromes. Circulation Research. 2014:114:1867-1879

33. Lahdentausta L, Leskelä J, Winkelmann A, et al. Serum MMP-9 diagnostics, prognostics, and activation in acute coronary syndrome and its recurrence. Journal of Cardiovascular Trans/ational Research. 2018:11:210-220.

34. Kai $\mathrm{H}$, Ikeda $\mathrm{H}$, Yasukawa $\mathrm{H}$, et al. Peripheral blood levels of matrix metalloproteases-2 and -9 are elevated in patients with acute coronary syndromes. J Am Coll Cardiol. 1998;32:368-372.

35. Inokubo $\mathrm{Y}$, Hanada H, Ishizaka H, Fukushi T, Kamada T, Okumura K. Plasma levels of matrix metalloproteinase-9 and tissue inhibitor of metalloproteinase- 1 are increased in the coronary circulation in patients with acute coronary syndrome. American Heart Journal. 2001;141:211-217.

36. Derosa G, D'Angelo A, Scalise $F$, et al. Comparison between metalloproteinases-2 and -9 in healthy subjects, diabetics, and subjects with acute coronary syndrome. Heart and Vessels. 2007;22:361-370.

37. Dumitriu IE, Baruah P, Finlayson CJ, et al. High levels of costimulatory receptors OX40 and 4-1BB characterize CD4+CD28null T cells in patients with acute coronary syndrome. Circulation Research. 2012;110:857-869.

38. Saigusa R, Winkels $H$, Ley K. T cell subsets and functions in atherosclerosis. Nature Reviews Cardiology. 2020;17:387-401.

39. Rezaee-Zavareh MS, Tohidi M, Sabouri A, Ramezani-Binabaj M, SadeghiGhahrodi M, Einollahi B. Infectious and coronary artery disease. ARYA Atheroscler. 2016:12:41-49.

40. Higuchi ML, Ramires JAF. Infectious agents in coronary atheromas: a possible role in the pathogenesis of plaque rupture and acute myocardial infarction. Revista do Instituto de Medicina Tropical de São Paulo. 2002:44:217-224

41. Shah PK. Plaque disruption and thrombosis: potential role of inflammation and infection. Cardio/ Rev. 2000;8:31-39.

42. Pesonen E, El-Segaier M, Persson K, et al. Infections as a stimulus for coronary occlusion, obstruction, or acute coronary syndromes. Therapeutic Advances in Cardiovascular Disease. 2009;3:447-454.

43. Thygesen K, Alpert JS, Jaffe AS, et al. Third Universal Definition of Myocardial Infarction. Circulation. 2012;126:2020-2035.

44. Musher DM, Abers MS, Corrales-Medina VF. Acute Infection and Myocardial Infarction. N Engl J Med. 2019;380:171-176

45. Ridker PM, Cushman M, Stampfer MJ, et al. Inflammation, aspirin and the risk of cardiovascular disease in apparently healthy men. N Engl J Med. 1997;336:973-979

46. Ridker $\mathrm{P}$, Hennekens $\mathrm{CH}$, Buring JE, et al. C-reactive protein and other markers of inflammation in the prediction of cardiovascular disease in women. N Engl J Med. 2000;342:836-843

47. Ridker PM. High sensitivity C-reactive protein: potential adjunct for global risk assessment in the primary prevention of cardiovascular disease. Circulation. 2001;103:1813-1818.

48. Ridker P, Rifai N, Rose L, et al. Comparison of C-reactive protein and low-density lipoprotein cholesterol levels in the prediction of first cardiovascular events. N Engl J Med. 2002;347:1557-1565.

49. Ridker PM, Buring JE, Cook NR, et al. C-reactive protein, the metabolic syndrome, and risk of incident cardiovascular events: an 8-year follow-up of 14,719 initially healthy American women. Circulation. 2003;107:391-397.

50. Koenig W, Sund M, Fröhlich M, et al. C-reactive protein, a sensitive marker of inflammation, predicts future risk of coronary heart disease in initially healthy middle-aged men. Circulation. 1999;99:237-242.

51. Coelho Graça D, Golaz O, Magnin J-L, et al. CRP-Based Cardiovascular Risk Assessment: New Conventional CRP Assay Fit for Purpose? The Journal of Applied Laboratory Medicine. 2018;2:952-959.

52. Danesh J, Wheeler JG, Hirschfield GM. C-reactive protein and other circulating markers of inflammation in the prediction of coronary heart disease. N Engl J Med. 2004;350:1387-1397.

53. Wang TJ, Gona P, Larson MG. Multiple biomarkers for the prediction of first major cardiovascular events and death. N Engl J Med. 2006;355:26312639.
54. Blankenberg S, Zeller T, Saarela O. Contribution of 30 biomarkers to 10 year cardiovascular risk estimation in 2 population cohorts: the MONICA risk, genetics, archiving, and monograph (MORGAM) biomarker project. Circulation. 2010;121:2388-2397.

55. Seo WW, Kim H-L, Kim Y-J, et al. Incremental prognostic value of highsensitive C-reactive protein in patients undergoing coronary computed tomography angiography. Journal of Cardiology. 2016;68:222-228

56. Kubo T, Matsuo Y, Hayashi $Y$, et al. High-sensitivity C-reactive protein and plaque composition in patients with stable angina pectoris: a virtual histology intravascular ultrasound study. Coron Artery Dis. 2009;20:531535

57. Sanchís J, Bodí V, Llácer A, et al. Relación de los valores de proteína C reactiva con los hallazgos angiográficos y los marcadores de necrosis en el síndrome coronario agudo sin elevación del segmento ST. Rev Esp Cardiol. 2004;57:382-387.

58. Inoue T, Kato T, Uchida T, et al. Local release of C-reactive protein from vulnerable plaque or coronary arterial wall injured by stenting. J Am Coll Cardiol. 2005;46:239-245.

59. Mani P, Puri R, Schwartz GG, et al. Association of Initial and Serial C-Reactive Protein Levels With Adverse Cardiovascular Events and Death After Acute Coronary Syndrome: A Secondary Analysis of the VISTA-16 Trial. JAMA Cardiol. 2019:4:314-320.

60. Lucci C, Cosentino N, Genovese S, et al. Prognostic impact of admission high-sensitivity C-reactive protein in acute myocardial infarction patients with and without diabetes mellitus. Cardiovasc Diabetol. 2020:19:183.

61. Suleiman M, Aronson D, Reisner SA, et al. Admission C-reactive protein levels and 30-day mortality in patients with acute myocardial infarction. Am J Med. 2003;115:695-701.

62. Morariu M, Márton E, Mester A, et al. Association Between Acute Inflammatory Response and Infarct Size in Stemi Patients Undergoing Primary PCl. Journal Of Cardiovascular Emergencies. 2018;4:140-146.

63. Lazzerini PE, Capecchi PL, Laghi-Pasini F. Systemic inflammation and arrhythmic risk: lessons from rheumatoid arthritis. Eur Heart J. 2017;38:17171727.

64. Ungprasert P, Srivali N, Kittanamongkolchai W. Risk of incident atrial fibrillation in patients with rheumatoid arthritis: a systematic review and meta-analysis. Int J Rheum Dis. 2017;20:434-441.

65. Ahlehoff $\mathrm{O}$, Gislason $\mathrm{GH}$, Jørgensen $\mathrm{CH}$, et al. Psoriasis and risk of atrial fibrillation and ischaemic stroke: a danish nationwide cohort study. Eur Heart J. 2012;33:2054-2064

66. Efe TH, Cimen T, Ertem AG, et al. Atrial Electromechanical properties in inflammatory bowel disease. Echocardiography. 2016;33:1309-1316.

67. Seferović PM, Ristić AD, Maksimović R, et al. Cardiac arrhythmias and conduction disturbances in autoimmune rheumatic diseases. Rheumatology. 2006;45:39-42.

68. Korantzopoulos P, Letsas KP, Tse G, et al. Inflammation and atrial fibrillation: A comprehensive review. J Arrhythm. 2018;34:394-401.

69. Wu N, Xiang $Y$, Wu L, et al. Association of inflammatory factors with occurrence and recurrence of atrial fibrillation: A meta-analysis. Int $J$ Cardiol. 2013;169:62-72.

70. Chung MK, Martin DO, Sprecher D, et al. C-reactive protein elevation in patients with atrial arrhythmias: Inflammatory mechanisms and persistence of atrial fibrillation. Circulation. 2001;104:2886-2891.

71. Rienstra M, Sun JX, Magnani JW, et al. White blood cell count and risk of incident atrial fibrillation (from the Framingham Heart Study). Am J Cardiol. 2012;109:533-537.

72. Weymann A, Ali-Hasan-Al-Saegh S, Sabashnikov A, et al. Prediction of new-onset and recurrent atrial fibrillation by complete blood count tests: a comprehensive systematic review with meta-analysis. Med Sci Monit Basic Res. 2017:23:179-222.

73. Shao Q, Chen K, Rha SW, Lim HE, Li G, Liu T. Usefulness of neutrophil/ lymphocyte ratio as a predictor of atrial fibrillation: a meta-analysis. Arch Med Res. 2015;46:199-206. 